East African Medical Journal Vol. 80 No. 9 September 2003

VITAMIN A DEFICIENCY AMONG KENYAN CHILDREN AS DETECTED BY CONJUCTIVAL IMPRESSION CYTOLOGY

R. M. Munene, MBChB, MMed (Ophth), Ophthalmologist, Kenyatta National Hospital, P.O. Box 29871- KNH, Nairobi, Kenya, H.S. Adala, MBChB, MMed (Ophth), DORCS (Lon), Technical Advisor, Sight First L.C.I.F. P.O Box 20731-KNH, Nairobi, Kenya, M.S. Masinde, MBChB, MMed (Ophth), Senior Lecturer, Department of Ophthalmology and F.S. Rana, MBChB, MMed (Path), Lecturer, Department of Pathology, College of Health Sciences, University of Nairobi, P.O Box 19676, Nairobi, Kenya

Request for reprints to: Dr. R.M. Munene, Kenyatta National Hospital, P.O. Box 29871-KNH, Nairobi, Kenya

\title{
VITAMIN A DEFICIENCY AMONG KENYAN CHILDREN AS DETECTED BY CONJUCTIVAL IMPRESSION CYTOLOGY
}

\author{
R.M. MUNENE, H.S. ADALA, M.S. MASINDE and F.S. RANA
}

\begin{abstract}
Objective: To determine the prevalence of Xerophthalmia among Kenyan children aged (four to seven) years in high risk using Conjuctival Impression Cytology and transfer. Design: A cross sectional community based study.

Setting: Mathare slum in Nairobi and Tiva/Ithiani area of Kitui.

Subjects: Children aged four to seven years residing in the above areas were assessed for both clinical and cytological features of vitamin A deficiency.

Results: Of the 342 children included in this study, 316 (92.0\%) were normal, five $(1.5 \%)$ had XN, 19 (5.9\% had XIA and two $(0.6 \%)$ had XIB. No signs of corneal Xerophthalmia were seen in this study. Conjuctival impression cytology and transfer (CICT) was used to asses for squamous metaplastic changes associated with Vitamin A deficiency (VAD). Seventy five $(\mathbf{2 3 . 1 \%})$ of the children were normal by CICT while $249(\mathbf{7 6 . 9 \%})$ were abnormal. In comparing the two areas of study, only $13.2 \%$ of the children in Mathare had normal CICT compared to $50 \%$ in Kitui. For each of the age groups studied there was significant difference between the two areas with children from Mathare being more deficient than those from Kitui.

Conclusion: VAD is a significant health problem in the high risk areas assessed by CICT in this study.
\end{abstract}

\section{INTRODUCTION}

Vitamin A deficiency is a major threat to life and site to millions of children worldwide. The association between high mortality and Vitamin A deficiency even at sub-clinical levels has led to increased awareness of sub-clinical disease. The fight against VAD is dependent on availability of data on geographical distribution, magnitude and severity of the problem. In the last two decades most research on VAD has shifted to assessment of sub-clinical disease due to it's implications on mortality.

Conjunctival impression cytology and transfer (CICT) is a method of obtaining surface cells of bulbar conjunctiva to stain and observe for cytological changes. It was first described by Egbert in 1977 (1). The method has since been used worldwide in the study of subclinical VAD as well as other ocular conditions Abnormal CICT pattern preceds ocular signs of Xerophthalmia making CICT a more sensitive test than use of clinical signs. The method has been shown to have high sensitivity and specificity, thus requiring a small sample size then used in mass screening. In this study, ClCT is being used for the first time in Kenya in assessment of sub-clinical Xerophthalmia.

The objectives of this study were: To determine the prevalence of Xerophthalmia in Kenyan children aged
(1-7) years, from selected areas using CICT and to determine the severity of bulbar conjunctival squamous metaplastic changes seen in children in the study.

\section{MATERIALS AND METHODS}

Two Xerophthalmia high risk areas in Mathare and Kitui were identified for this study. Mathare is one of the largest slums in Nairobi. The slum has some of the lowest income earners in the urban context. There is no proper sanitation, latrines are sub-standard and water is bought from vendors. The main source of income is casual employment for the household head. All the food eaten is bought using the meagre resources available. In Kitui, Ithiani and Tiva areas were assessed. The main source of income in this area is food crop farming. With the area experiencing dry weather for the greater part of the year, vegetable sources of Vitamin A are usually not available in sufficient amounts.

In this cross-sectional community based study, a total of 342 children aged (4-7) years drawn from Mathare and Kitui were assessed. Of these 281 were from Mathare while 61 were from Kitui. Children aged less than four years were excluded due to the technical difficulty of performing CICT at this age. Children with ocular disease affecting the conjunctival epithelium e.g. conjunctivitis were excluded as this affects the cytological appearance of the conjunctival epithelium. Subjects were examined for both clinical and cytological changes of VAD. Clinical features of VAD were 
recorded using WHO grading of Xerophthalmia. Pathological (cytological) changes were graded by T'sengs classification of conjunctival squamous metaplasia (see appendix). CICT from inferotemporal conjuctiva was done using cellulose acetate paper. The paper was later stained using (a modified) PAP smear procedure. Diagnosis of VAD was based on scarcity/absence of goblet cells as well as presence of squamous conjunctival metaplasia.

\section{RESULTS}

In this study 342 children were examined. Two hundred and eighty one were drawn from Mathare slum while 61 were from Kitui. A hundred and forty nine were males and 193 were females.

Table 1

Age distribution of the children in the study $(n=342)$

\begin{tabular}{lll}
\hline Age (years) & No. & $\%$ \\
\hline $4.0-4.9$ & 73 & 21.3 \\
$5.0-5.9$ & 91 & 26.6 \\
$6.0-6.9$ & 79 & 23.2 \\
$7.0-7.9$ & 99 & 28.9 \\
\hline Total & 342 & 100 \\
\hline
\end{tabular}

Table 1, shows the age distribution of the children in the study. On clinical examination, $316(92.0 \%)$ of the children were normal, five $(1.5 \%)$ had $19(5.9 \%)$ had XIA and two $(0.6 \%)$ had XIB. No corneal Xerophthalmia was seen in this study (Table 2). Of the 26 children with clinical Xerophthalmia, 15 were males while 11 were females(M:F ratio 1.3:1).

Table 2

Clinical distribution of Xerophthalmia in the study population $(n=342)$

\begin{tabular}{lll}
\hline $\begin{array}{l}\text { Clinical } \\
\text { Stage }\end{array}$ & No. & $\%$ \\
\hline Normal & 316 & 92.3 \\
XN & 5 & 1.5 \\
XIA & 19 & 5.9 \\
XIB & 2 & 0.6 \\
\hline Total & 342 & 100 \\
\hline
\end{tabular}

Table 3

Age distribution of the clinically Xerophthalmia cases $(n=26)$

\begin{tabular}{llll}
\hline Age (years) & XN & XIA & XIB \\
\hline $4.0-4.9$ & 0 & 6 & 0 \\
$5.0-5.9$ & 1 & 4 & 1 \\
$6.0-6.9$ & 3 & 5 & 0 \\
$7.0-9.9$ & 1 & 4 & 1 \\
\hline Total & 5 & 19 & 2 \\
\hline
\end{tabular}

Clinical Xerophthalmia was observed in all the age groups studied, Table 3, and there was no decline of clinical Xerophthalmia with increasing age.

In this study CICT stage $\mathrm{O}$ and I (by Tseng's classification) was considered normal while stages 2 to 5 was abnormal. Cytology samples were considered adequate if they covered at least one quarter of one microscope field (x 4 objective). Out of 342 examined, $324(97.5 \%)$ had adequate material for cytology. Ten slides were misplaced while eight slides had no cell yield. Of the 324 cytology samples read, 75 (23.1\%) were normal (stage 0 and I) and 249(76.9\%) were abnormal (stage 2 to 5 ).

Table 4

Cytological classification in relation to age

\begin{tabular}{llllll}
\hline Stage & $4.0-4.9$ & $5.0-5.9$ & $6.0-6.9$ & $7.0-7.9$ & Total \\
\hline 0 & 6 & 4 & 7 & 9 & 26 \\
1 & 9 & 10 & 11 & 19 & 49 \\
2 & 8 & 7 & 6 & 9 & 30 \\
3 & 12 & 15 & 9 & 15 & 51 \\
4 & 10 & 11 & 9 & 11 & 41 \\
5 & 26 & 39 & 31 & 31 & 127 \\
\hline Total & 71 & 86 & 73 & 94 & 324 \\
\hline
\end{tabular}

There was no decline in abnormal cytology with increasing age.

Table 5

Clinical examination by cytological stage $(n=324)$

\begin{tabular}{lllll}
\hline Stage & Normal & XN & XIA & XIB \\
\hline 0 & 25 & 0 & 1 & 0 \\
1 & 47 & 0 & 2 & 0 \\
2 & 30 & 0 & 0 & 0 \\
3 & 47 & 0 & 4 & 0 \\
4 & 38 & 0 & 3 & 0 \\
5 & 111 & 5 & 9 & 2 \\
\hline
\end{tabular}

The children with XN and Bitot's spots had severe squamous metaplasia Tseng' stage 5 .

Table 6

Comparing clinical examination with cytological examination

\begin{tabular}{lll}
\hline & $\begin{array}{l}\text { Cytologically } \\
\text { Abnormal } \\
\text { No. \% }\end{array}$ & $\begin{array}{l}\text { Cytologically } \\
\text { Normal } \\
\text { No. \% }\end{array}$ \\
\hline Clinically Abnormal & $23(88.5)$ & $3(11.5)$ \\
Clinically Normal & $226(75.8)$ & $72(24.2)$
\end{tabular}

Clinical Examination $\quad$ Sensitivity: $23 / 249=9.2 \%$ Specificity: $72 / 75=96 \%$

The specificity and sensitivity of CICT could not be reached since serum retinol was not done. This was due to financial constraint. 


\section{Table 7}

Cytological changes in the various age groups in the two areas

\begin{tabular}{lllll}
\hline $\begin{array}{l}\text { Age } \\
\text { Group(yrs) }\end{array}$ & N & $\begin{array}{l}\text { Abnormal } \\
\text { No. }\end{array}$ & $\begin{array}{l}\text { Cytology } \\
\%\end{array}$ & P-value \\
\hline $4.0 / 4.9$ & M 61 & 52 & 85.2 & 0.0209 \\
& K 10 & 5 & 50.0 & \\
$5.0 / 5.9$ & M 71 & 63 & 88.7 & 0.0065 \\
& K 13 & 7 & 53.8 & \\
$6.0 / 6.9$ & M 61 & 45 & 80.3 & 0.0231 \\
& K 12 & 6 & 50.0 & \\
$7.0 / 7.9$ & M 67 & 52 & 77.6 & 0.005 \\
& K 27 & 13 & 48.1 & \\
\hline
\end{tabular}

$\mathrm{M}=$ Mathare $\mathrm{K}=$ Kitui

On comparing pathological changes in various age groups in the two areas (Table 6), $13.2 \%$ of the children in Mathare were normal compared to $50.0 \%$ in Kitui. This was statistically significant $\mathrm{p}<0.05$.

\section{DISCUSSION}

Of the children with clinical Xerophthalmia, five $(1.5 \%$ ) had night blindness $\mathrm{XN}$ (Table 2). This is above the WHO cut off level of $1.0 \%$ for $\mathrm{XN}$ as an indicator of Xerophthalmia severity. Interviewing the guardian/ parents was used to assess $\mathrm{XN}$ in this study. While this is a very subjective method as it depends on observation and recall, it is more practical than use of objective methods for field surveys (2). Farbo in Bayone got XN prevalence rate of $2.7 \%$ while Klem in Philippines reported XN prevalence of $1.6 \%(3,4)$. An earlier study in Kenya had XN prevalence of $2.8 \%$, but this was not a community based study (5). The $\mathrm{XN}$ value in this study compares well with that of Philippines. Children with XN have been shown to have mortality rates of up to four times higher than normal (6). Nineteen $(5.5 \%)$ of the children had XIA. Though an important finding XIA is not used by WHO as a criteria for VAD assessment. This is due to inte-observer and intra-observer variation in describing XIA and the existence of several confounders e.g allergy. To different observers the term xerosis ranges from abnormal cytology through dryness of the conjuctiva to keratinization.

Two children $(0.6 \%)$ had Bitot's spots. They included a seven year old male from Mathare and a five year old female from Kitui. These may have been non-responsive Bitot's spots, which are usually found in older children without any other features of VAD. To some people they represent a stigmata of earlier deficiency while to others, they represent insult by environmental factors like ultra-violet light in high altitudes and chronic eye infections. There was no sign of corneal Xerophthalmia in this study. This was not unexpected. Corneal Xerophthalmia is associated with a $60 \%$ mortality rate. It is usually associated with severely malnourished children and is also a disease of children younger than three years. This study was community based and on 'normal' and older children, making the chances of finding corneal Xerophthalmia low.

Clinical Xerophthalmia did not decrease with increasing age (Table 3). This is despite the fact that Xerophthalmia is mainly a disease of children less than age five years. It is expected that the older children are free of the factors contributing to VAD like diarrhoeal diseases, poor feeding habits/limited access to vitamin A rich foods etc. This however may not apply in this case as food sources are generally, inadequate and there are frequent infectious diseases leaving the older child still susceptible to VAD.

Conjunctival metaplastic changes usually precede clinical Xerophthalmia and can be used as an indicator of sub-clinical disease. In this study, Tseng's staging of conjunctival squamous metaplasia was used for analysis of conjunctival samples. Tseng's stage 0 and 1 are considered normal while stages 2 through 5 are abnormal. The cytology yield in this study was $97.5 \%$. The figure compares well with figures of $92.7 \%$ in a Bayonne study and $93.7 \%$ in Nigeria(9). It is well above the $61.6 \%$ by Danks et al. in Kiribati (10). Failed conjunctival cell harvest is due to excess lacrimation with subsequent failure of cellulose acetate paper adhesion to the conjunctiva. It can also be due to failure to flatten the paper on the conjunctiva properly, thus failing to get the necessary apposition for cell harvest. In good hands the technique is highly reliable (as shown by the high harvest rate of $97.5 \%$ in this study).

Of the 324 cytology samples read, $75(23.1 \%)$ were normal (stage 0 and 1) while 249(76.9\%) were abnormal (stage 2 to 5).WHO criteria of abnormal CICT as a health problem cut-offs at:

(i) $<20 \%$ abnormal CICT as mild deficiency.

(ii) $>20-40 \%$ abnormal CICT as moderate deficiency. (iii) $>40 \%$ abnormal CICT as severe deficiency.

The high risk, areas assessed in this study thus have severe sub-clinical deficiency by WHO cut-off. This figure is well above $57.4 \%$ in a community based study by Perkins in Mali and $22.0 \%$ in Malawi $(11,12)$ Khandait et al. reported $37.5 \%$ abnormal CICT in Naigpur slum (13). There was no decline in abnormal cytology with increasing age (Table 4). This was unexpected. In this study, high risk areas were being assessed and VAD predisposing factors (e.g. infections and restricted diet) expected to normalise with increasing age were outweighed by unavailability of vitamin A resources.

One hundred and forty nine (47.4\%) of the clinically normal children had severe metaplastic changes (stage 4 and 5). This implies that clinical examination though easy and cheap to perform, is only useful in detection of gross morphological changes. The children with XN and XIB were cytologically graded at T'sengs stage 5 (Table 5). Abnormal CICT has been shown to be related to $\mathrm{XN}, \mathrm{XIB}(14)$. The sensitivity of clinical 
examination in this study was $9.2 \%$ while it's specificity was $96.0 \%$ (Table 6). The advantage of clinical examination having a high specificity is outweighed by the fact that clinical examination is only useful where there are gross VAD changes thus missing out sub-clinical disease. This is despite the fact that subclinical disease is more prevalent and is associated with high mortality rates. Clinical examination has remained the method of use in VAD diagnosis in many developing nations since it is cheap and easy to perform. The method is disadvantaged in that it needs experience and a large sample size when used in field surveys. The sensitivity and specificity of CICT in this study could not be determined as serum retinol levels were not performed. Khan et al. in a study done in Dakar found both the sensitivity and specificity of CICT to be $100 \%$ (15).

For each of the age groups studied, there were more abnormal cytology samples in Mathare than Kitui. Overall $13.2 \%$ of the children from Mathare had normal cytology compared $50 \%$ in Kitui. For each of the age groups studied, there were more children in Mathare with abnormal cytology compared to Kitui $\mathrm{p}<0.005$ (Table 7). Kitui is considered to be a very dry area but at the time of this study there had been rains for around six weeks and the gardens had a lot of vegetables. Reversal of abnormal CICT with vitamin A supplementation usually takes about eight weeks. It is possible that the cytology results would have shown more deficiency if taken during the dry season when the vegetables sources of Vitamin A are low. In conclusion:

(i) Clinical Xerophthalmia is of public health significance in high risk areas of Kenya studied.

(ii) There is severe sub-clinical Xerophthalmia as detected by CICT in high risk areas of Kenya assessed.

Over and above this study there is need for a national wide study of Xerophthalmia prevalence in Kenya using both clinical signs and CICT. With the enormous amount of VAD seen in this study, there is need to continue with 'targeted' prevention of VAD. Finally there is need to sensitize ophthalmologist and other health workers on the use of CICT since it is cheaper than other biochemical methods in use.

\section{ACKNOWLEDGEMENTS}

The authors are grateful to Rose Odhiambo and the late George Olong'o for all their ideas and input in the laboratory processing of the specimens.

\section{REFERENCES}

1. Egbert, P. and Lauber, S. A simple conjunctival biopsy. Amer. J. Opthalm. 1984; 84:798-801.

2. Mclaren, D., and Martin, F. Sight and life manual on vitamin A. deficiency disorders. Defination of xeropthalmia. P43-45.

3. Farbo. S., Resnikoff, S., Peyramaure, F. et al. Xeropthalmia.
Identification of populations at risk. Sante. 1995; 5:159-161.

4. Klem, R. D., Villate, E.E., Tuason, C.S., et al. A prevalence study of xeropthalmia in the Philippines. Implications for supplementation strategies. South-East Asian J. Trop. Med. Public. Health. 1993; 24:17-23.

5. Duku, A.W. Xerophalmia in high areas of Kenya. M.Med. Dissertation, University of Nairobi, 1989.

6. Sommer, A., Tawotjo, I. and Hussaini, G. Increased mortality in children with mild Vitamin A deficiency. Lancet. 1983; 2:585-588.

7. Mclaren, D., and Paton, D. Bitots spots. Amer. J. Ophthal. 1960; 50:568-574.

8. Sinha D. P., and Bang, F. B. Seasonal Variation in signs of VAD in rural West Bangal children. Lancet. 1973; 2:228-231.

9. Usen, S.O., Akinyinka, O.O., Akani, O.A., et al. Xeropthalmia. Identification of populations at risk. Sante. 1995; 5:159-161.

10. Danks, J., Kaufman, D., and Rait, J., A clinical and cytological study of vitamin A deficiency; in Kiribati. Aust. N. Z. J. Ophthal. 1993; 21:15-18.

11. Perkins, A. Evaluation of vitamin A deficiency in Yelimane circle of Mali. Tropical Doctor. 1994 ; 24:70-72.

12. Chirambo, M. C., Escoute, A.J., Luzeau, R. et al. Assessment of vitamin A deficiency in Republic of Malawi by Impression cytology method. Intern. J. Vitamin and Nutrition Res. 1991; 61:10-16.

13. Khandait, D .W., Vasudeo, N.D., Zodpey, S.P., et al. Subclinical vitamin A deficiency in Naigpur, India. South East Asia J Trop. Med. Public Health. 1998 ; 29:289-292.

14 Natadistara, G., Wittpenn, J.R., Muhilal. et al. Impression cytology; a practical index of vitamin A status. Amer. J. Clin. Nutr. 1998; 48:1271-1276.

15. Khan, A.N., Huda, S., Ahmed, A.N., et al. Detection of early Xeropthalmia by Impression cytology and Rose bengal staining. A comparative study. Bangl. Med. Res. Bull. 1992; 18:1-11.

\section{APPENDIX}

Tseng's Classification for conjuctival squamous metaplasia Stage 0. Normal conjunctival epithelium. Moderate number of goblet cells scattered among uniform non-goblet epithelial cells. The nucleus cytoplasmic ratio is $1: 1$.

Stage 1. Early loss of goblet cells without keratinization. There is decrease in goblet cell density with mild enlargement of non-goblet epithelial cells. Nucleus cytoplasmic ratio is $1: 2$ to $1: 3$.

Stage 2. Total loss of goblet cells without keratinization. No goblet cells are seen and epithelial cells are moderately enlarged and flattened (squamoid) The cytoplasm stains blue-green to mild pinkish colour with a nucleus: cytoplasm ratio of $1: 4$.

Stage 3. Early and mild keratinization. All epithelial cells are marked squamoid with cytoplasm being pink. Nucleus to cytoplasm ratio is $1: 6$.

Stage 4. Moderate keratinization. All epithelial cells are enlarged and squamoid. Densely packed keratin filaments can be seen. Nucleus/cytoplasm ratio is 1:8.

Stage 5. Advanced keratinization. More cells are keratinized with markedly pyknotic nuclei and shrunken cytoplasm. In some cells nucleus is lysed or missing. 